\title{
COLLECTIVE WRITING: AN INQUIRY INTO PRAXIS
}

\author{
PETAR JANDRIĆ \\ pjandric@tvz.hr \\ Zagreb University of Applied Sciences, Zagreb \\ (corresponding author) \\ NESTA DEVINE \\ School of Education, \\ Auckland University of Technology, Auckland \\ ELIZABETH JACKSON \\ Faculty of Education, \\ University of Hong Kong, Hong Kong \\ MICHAEL A. PETERS \\ Faculty of Education, \\ University of Waikato, Hamilton \\ GEORGE LĂZĂROIU \\ Institute of Interdisciplinary Studies in \\ Humanities and Social Sciences, New York; \\ Spiru Haret University, Bucharest \\ RAMONA MIHĂILĂ
}

Department of Foreign Languages and Literatures, Dimitrie Cantemir Christian University, Bucharest

KIRSTEN LOCKE

Faculty of Education, University of Auckland, Auckland

RICHARD HERAUD

Faculty of Education, University of Waikato, Hamilton

ANDREW GIBBONS

School of Education, Auckland University of Technology, Auckland

ELIZABETH GRIERSON

College of Design and Social Context,

RMIT University, Melbourne

DANIELLA J. FORSTER

School of Education, University of Newcastle, Newcastle

JAYNE WHITE

Faculty of Education, University of Waikato, Hamilton 
GEORGINA STEWART

School of Education, Auckland University of Technology, Auckland

MAREK TESAR

Faculty of Education, University of Auckland, Auckland

SONJA ARNDT

Faculty of Education, University of Waikato, Hamilton

SUSANNE BRIGHOUSE

EPAT Editorial Office

LEON BENADE

School of Education,

Auckland University of Technology, Auckland

\begin{abstract}
This is the second text in the series collectively written by members of the Editors' Collective, which comprises a series of individual and collaborative reflections upon the experience of contributing to the previous and first text written by the Editors' Collective: 'Towards a Philosophy of Academic Publishing.' In the article, contributors reflect upon their experience of collective writing and summarize the main themes and challenges. They show that the act of collective writing disturbs the existing systems of academic knowledge creation, and link these disturbances to the age of the digital reason. They conclude that the collaborative and collective action is a thing of learning-by-doing, and that collective writing seems to offer a possible way forward from the co-opting of academic activities by economics. Through detaching knowledge creation from economy, collaborative and collective writing address the problem of forming new collective intelligences.
\end{abstract}

Keywords: collective writing; collective authorship; collaborative writing; Editors'

Collective; collective intelligence; co-production; public goods; academic labour

\title{
Introduction
}

Petar: This is the second paper in the series of texts collectively written by members of the Editors' Collective - a small New Zealand-based organisation comprised of editors and reviewers of academic journals, most in the fields of education and philosophy. ${ }^{1}$ The first paper in the series, 'Toward a philosophy of academic publishing' (Peters, Jandrić, Irwin, Locke, Devine, Heraud, Gibbons, Besley, White, Forster, Jackson, Grierson, Mika, Stewart, Tesar, Brighouse, Arndt, Lăzăroiu, Mihăilă, Bernade, Legg, Ozolins, and Roberts, 2016) was an experiment in the collective writing process. The experiment consisted of two stages. In the first stage, each contributor (or group of contributors) was invited to write 500 words on a topic that was initially arrived at through discussion and sequenced by agreement. The idea behind the process was for contributors individually or in groups to submit their work to a moderator (Richard Heraud) who sequenced the 
contributors as they became available and to post it to the Collective. In the second stage, before the final discussion section was written, the paper was submitted to open review by two senior members of the journal Educational Philosophy and Theory (Professors John Ozolins and Peter Roberts). Their remarks were also restricted to 500 words, and included at the end of the paper. In sum, the paper was collectively written by 23 authors.

This second paper, moderated by Petar Jandrić, is a follow-up inquiry into the process of collaborative writing. All contributors to 'Toward a philosophy of academic publishing' were invited to reflect upon their experience. Apart from a simple invitation to contribute, authors received no further instructions about length, format, or nature of the requested contribution. Based on collective e-mail discussion, the paper is structured as follows:

1. Introduction

2. Setting the scene

3. Experiences and challenges - contributors

4. Experiences and challenges - moderators

5. Emerging themes and challenges

6. Discussion

7. Conclusion.

During the process of collective writing and moderation, the planned structure of the article has organically changed and developed, illustrated by two characteristic examples. Firstly, the section Setting the scene was not originally planned. Given a completely open call, however, contributors approached the theme in very different ways. Several contributors understood the theme in fully theoretical terms, and contributions by Nesta, Elizabeth J., and Michael seemed to draw an appropriate scene for the rest of the article. Therefore, these contributions have naturally emerged as a standalone section. Secondly, during the process of collecting contributions, the moderators of 'Toward a philosophy of academic publishing' (Richard) and 'Collective writing: An inquiry into praxis' (Petar) shared experiences pertaining to their role in the process of collective writing. Richard suggested that moderators' experiences might provide another useful perspective for the research and the collective agreed, so a section on moderators' experiences has been added.

\section{Setting the scene}

Nesta and Elizabeth J.: There is no question in our minds that writing in collaboration can be an extremely productive process. Discussing in collaboration, whether or not the writing is collaborative, can also be very productive. Indeed, if we take this series to its natural conclusion, then thinking with others, that is to say, using language whether by oral/aural exchange or reading/writing exchange is a productive way to think, and if we consider the relation between language and 
thinking to be deeply embedded, quite possibly these amount to the only way we can think, since to use language is to use the thinking of our forebears. As soon as we use a word, and expect it to be understood, we enter into an act of collaboration with both those who have used the word previously and those who are part of the same language community engaged in receiving that word, whether by listening or reading, in the here and now.

Given this state of affairs, since all acts of reading, writing, speaking, listening are collaborative by definition, why should we now, at this moment, be emphasizing collaboration in research and writing?

It seems that this is a natural and perhaps a necessary rejoinder to the emphasis put upon individualism in academic life. The neo-liberal impulse to accountability inspires managers to counting the indicators of productivity - students taught, students supervised, papers written, networks joined, research teams partaken in.... and the overwhelming effect is to emphasise the isolated individualism of the performer-academic, even when they are being exhorted to join things. So to collaborate, especially to collaborate in ways that obscure who wrote what, is in itself a dissident act, even as, at the same time, it fulfils a repeated theme, almost a requirement, of the neo-liberal university. There will be rewards for collaboration but - here is the point of resistance - the university will never know if they were justified or not.

We have to consider, however, some other dimensions to this collaborative project. As teachers we should be aware that for some of our students, and presumably for some of our colleagues, co-operation is significantly more challenging than it is for others. For the autistic child, co-operation, social skills and these are what make collaborative writing, like most other forms of collaboration, actually work - are often painfully acquired, and only then through deliberate teaching, repetition and reward - a combination of Aristotelean habituation and Behaviorist reinforcement. Like the Flexible Learning Environment, which is based on a utopian notion of happy little children working independently and energetically side by side, collaboration can pose all sorts of challenges, anxieties, pitfalls to the person who does not have the necessary preliminary training and ability to exclude extraneous 'noise'. So, in our view, collaboration should be treated with care: when it works, it is very very good, and when it does not, people should be able to go off quietly to do their own thing.

We can take one further step back as we consider the educational implications of valuing collaboration in thinking and producing research and other professional and vocational outputs (for teaching and other processes). If we see neo-liberalism as a historical process in higher education, professional and work life, over time scholars have been discouraged from casual chats in the pub after seminars and informal social networking. Accountability demands for individual outputs have become entrenched and intensified in the lives of academics within a new hidden curriculum of job scarcity and uncertainty (which may be particularly felt by junior academics). Time spent in philosophical, abstract, and informal discussion of ideas 
and work with colleagues in one's fields and relevant subfields now might be seen as time not spent in direct processes of accountable work production. If it does not wind up on the $\mathrm{CV}$, it does not 'count.'

Individualism in counting and measuring results in higher education at the same time creates an environment where competition rather than collaboration is prioritized, despite the discourse promoting the latter that can be found in every university's policies. Working under the gun, peer review transforms from an ideally constructive process of collaboration in developing and communicating new ideas in one's field, into more discrete events of evaluating others harshly against her own criteria for success, carried out in an irate mood as she feels pressured for time for such 'service' work.

In such an environment scholars who wish to promote collaboration at all levels of academic and educational life are disabled by material pressures, lack of experience, lack of necessity, and lack of human capital and human resources. Who can teach a new generation to be more collaborative and to value collaboration, and what can motivate them to do so, to push against the grain? Here the benefits of collaboration must be considered from a philosophical perspective against the contemporary neo-liberal backdrop of higher education, scholarly publishing, and academia, moving away from a pedagogy of jigsaw puzzling (each student has one clue and fits them together to solve the problem), to elaborate collaboration as a normative practice and critically trace what is meant by collaboration from a holistically individual, psychological, social, theoretical, and economic-political perspective.

Michael: The modern concept and philosophy of the author is defined primarily in a legal definition as the writer and author of 'original works' under copyright as a form of intellectual property. It was this view that also encouraged a philosophical view about the meaning of the text as an expression of authorial intention. In school I was bemused at the game of literary criticism that appeared to be reducible to guessing the author's intention. How was I to guess Wordworth's intention when he poetised about Nature from his experience in the highly manicured Lake District? For a boy from an untamed pastoral New Zealand landscape in retrospect this seems preposterous. I never understood Wordworth until I visited his house in the Lake District and read his poems in that context.

Both Barthes and Foucault have challenged the Romantic idea and the argument that a text can be attributed to any single author. Certainly, given the context and the fact that the author herself is a product of an historical context there is no reason to believe that reference to the author's intentions exhausts the meaning of a text or even provides the best and only principle of interpretation, even if the first blush of 'the death of the author' seems to have abated. I was brought up and educated at a time when the notion of the author was an unassailable truth and all knowledge of the text flowed from the primacy of this principle. ('Yes but Michael, what did Shakespeare mean?' I hear my teacher saying with annoyance). That the notion of the author might be a social construction had to wait for another 
generation and until the idea of 'intertextuality' (the text as a product of other texts) took hold.

The author from the Old French auctor meaning 'father, author, originator, creator, instigator,' and the Latin auctorem meaning 'enlarger, founder, master, leader' and literally 'one who causes to grow' was not always associated with the writer or the scribe or the notion of self and its expression. (The meaning of the text betrays its patriarchal culture.) Only when the text was being canonized did the notion of author as originator, as genius and a man of letters come into being at the time when a set of legal definitions began to shape modern literary culture.

If the notion of author is socially constructed then it can be constructed otherwise especially in the context of the contemporary university. It can also upset the institution's neoliberal ethos of privatization and research monitoring and evaluation based on the author of journal research papers. The Editors' Collective seemed a great space to experiment with collective authorship and now the first experiment is almost complete it is reasonable to reflect on the process which I found quite liberating. Of course, there have been other experiments in collective creations - literary ones like the James I Bible, the edited collection, the encyclopaedia, the orchestra, and movie - and also more recently experiments with distributive writing often developed through social software. But principally, my interest really stems from an interest in collective intelligence in an age of technologically-enhanced interconnectivity. I like the concept and the process and felt that 'progress' can be made quickly from among those who make up the ecosystem.

As to the question of subjectivity I would argue that the success of the model is a result of intersubjectivity - the new platform for learning. Collective authorship through collaborative writing is already well advanced in digital storytelling (Sevilla-Pavón, 2015) which 'can be related with the creation of a new collaborative culture resulting from the advent of Web 2.0' and enables 'participants to switch back and forth between the roles of Writer, Editor, Reviewer, Team Leader and Facilitator.' This conception surely works against the Romantic notion of individual and heroic authorship and begins to unthread the philosophy of locating meaning in the intentions of an author, rather than in the interactive system of which the reader is a constituent and necessary part.

\section{Experiences and Challenges - Contributors}

George: I have co-authored a lot of published papers so far. We may create jointly as an addition and an upgrading of our deep acquaintanceships: the practice and the investigation of teamwork may be undertakings of destabilization and of liberatory implication (Barnett, 2015), constituting a difficult task to established research practices in the humanities. An obstacle to scholarly partnership in the humanities is the persistence of the notion of primary and secondary authorship (Ede \& Lunsford, 1990). In joining forces on writing, co-authors should pursue a definite 
choice, without repudiating their separate beliefs or suppressing their disagreements to one another's positions, finding out to pay attention to each other, developing each other's judgments, and reaching at a manner of communicating as a group what we rely on. Sometimes our collaborative writing cannot be disentangled into components that we want to ascribe to one or the other of us (Haddad \& Wang, 2015): however, each of us takes the main accountability for various elements, the research output entirely is the result of shared endeavours and networking of initiatives (Field Belenky et al., 1997).

Mass authorship makes it more difficult to identify who did what and who is worthy of the real recognition for a leap forward (Lăzăroiu, 2015), or disapprobation for misbehaviour (there may be no manner to clarify how significant each co-author might be). Credit on an academic piece counts greatly in employment, promotion and tenure decisions. The position of first author generally provides the most prominence, distinguishing the individual who participates the most to the execution of the paper, whereas the last author is frequently the senior scholar who supervises the research enterprise. Numerous peer-reviewed outlets demand that all co-authors inspect and approve the final version of a manuscript, and clarify their contribution. The latter should also be responsible for all features of the research process. (Lee Hotz, 2015)

Ramona: While co-authoring has many advantages: developing new ideas, improving research methods, or sharing the workload, there are also a lot of disadvantages. On the one hand, it is important to have an explanatory note to mention who the main author is (in fact) or to underline each author's contribution. Some universities have different evaluation criteria for scholar's research activities in terms of co-authoring, thus the main co-author may get $60 \%$ out of the percentage of the article, while the rest of $40 \%$ is divided for the rest of the coauthors, or, in the happy cases, all the co-authors get an equal share out of the percentage. In terms of citation, there is also a little disadvantage when there is mentioned only the name of the first co-author while the others are hid behind the phrase et al. Sometimes, in the social sciences and humanities the authors are listed in alphabetical order to indicate equal contributions (if specified in the footnotes) or are listed in the order of substantive contributions they have made.

Kirsten and Nesta: 'Will you write with me?' A simple question, said over a cup of tea at a conference in Christchurch at the start of the week. By the end of that same week I am sitting in Nesta's office in Auckland, cup of tea beside the computer. We get down to business quickly. We talk and I type. We finish each other's sentences, sometimes orally, sometimes on my laptop screen. Sentences take visual shape in black and white as we dab together at our colourful palette of ideas: Let's move away from historicity, let's critique the determinism of development, let's see what remains the same, what changes. We're on the same page, our words and us. 
This collaborative writing process is one that draws on a specific history that manifests in this physical meeting of minds. We live and work in Auckland and it makes sense to book in an appointment to write together as a good excuse to meet. This may well be different to the other collaborations in this series. For Nesta and me, technology takes a back seat in favour of the chance to converse and think together in person. Does this make the collaborative process easier? Perhaps. There is something specific about the pacing of a conversation that takes place in physical proximity; something luxurious that feels almost indulgent when contrasted with the digitally mediated context of our writing lives. We can spark off each other and dip into the performative dimension of a dialogue that unfolds in real time and unfurls around a ten-year history of meeting, conversing, thinking, and sharing stories of life and academia in the learned society that is PESA.

'We should have recorded this,' I say at the end. It would have been interesting to see this collaboration played back to us to analyse. We may have been able to pinpoint the negotiations that take place to structure the argument, or the moments when we pass our ideas for the other to catch, discard or carry forward. For two people who enjoy the art of conversation, we stay remarkably and steadfastly focussed on the task at hand. Perhaps the recording would have caught the snippets of conversation that make reference to our busy academic lives as we write about the lineage of academic thought expressed through the form of the scholarly journal. In this way collaboration encompasses the marginalia of academic lives like ours, written around the labour of academic writing.

What did we learn? Academic writing in the humanities particularly is often viewed as an individual pursuit. The bespectacled academic staring at a screen with their fingers gliding over a keyboard may have replaced romantic images of the scholar bent over parchment with quill in hand, but both these images capture the ascetic dimension to academic writing. While the technical tools have changed, much of what we consider to be the nature of academic writing still fits these individualistic pictures in essence if not in truth. Perhaps this project brings in a more postmodern notion of writing as bricolage, where small pieces of collaborative writing fragments are knitted together by a common history and shared membership of a learned society that joins together disparate thought and common intentions.

Nesta: Because I have had the privilege of taking part in two of these collaborative experiments, one by email and one with the participants together in person, I have the luxury of being able to compare the process. Although both have been pleasant experiences, they have been quite different. The email process has involved one person writing the initial paragraph, then each person penning separate paragraphs, perhaps altering sentences to ensure that they fit together. So the result may be in some sense schizoid - the joins are probably clearly visible! With the collaboration between Kirsten and myself I can now identify the ideas that each brought to the table (the big working dining table in my office), but it would be very difficult to unravel the sentences and ascribe them to one or the other of us. The email process 
is more like the original methodology of the academic letter, the face-to-face conversation more like the dynamic interchange of ideas that causes immediate change in thinking. In both cases the respect that each has had for the partner in the process has been vital to the success of the enterprise, and the existence of a shared language has also been essential.

Richard: While this was first piece of so-called collaborative writing that I have written with Andrew, this is not the first time we have written together. We have written in various forms off and on over the last decade or so. This is not the reason either why we wrote together on this occasion: when the idea to write collectively was proposed, Andrew was sitting beside me - simply that: it might have been someone else, someone I had never written with before, and this would have been an equally attractive proposition. If, however, it were someone else, my experience of writing with Andrew would have been an influence as it is with him that I learned that the capacity to write together is more founded on the nature of friendship than it is on an understanding of the problem of writing. In other words, the problem of writing could be thought of as a problem of friendship. To write together, we therefore need new friends.

In the context of such a friendship as Andrew's and mine, it does not matter who begins, who assumes the protagonism, who provides the key to or the crux of the argument. We do not have a system for articulating something, for putting it together, for completing something - our friendship functions perfectly without a system: we are comfortable with our uncertain knowledge of each other, realizing that the uncertainty must in fact be preserved. A friendship as a basis for working together recovers writing from the ambit of work, from conventions, from the obligation of a certain type of outcome, from the critical self-consciousness that informs the attitude that one gives to a good performance, to a career. A friendship, as a basis for writing enables us to retrieve writing from the regime of work and to return it, as an act, to the realm of action that speaks - making it once again possible to reveal something that the regime of work is unable to produce on its own.

In everything said thus far, a key element is missing: the notion that an idea has more possibilities if it is paradoxical in nature. Perhaps our friendship would die a banal death without paradox. This said; this is not something we fear as certain conditions tend to work in our favour. Disagreement is more useful than agreement; we use different tools - each invisible to the other - to turn the idea over (the cow pat). The idea's epistemological arrival is both irreconcilable and yet formed under the same sky. Hence we begin from a sensation of having already broken from the mould of its form - the mould of the idea. Friendship cannot exist in an experience of anarchy. We are adventurous not only because the search for a way would be stilted without adventure. Adventure is to change the face of what already exists. And we do this not for ourselves, although we ourselves do it.

It is not a philosophical friendship or even a political friendship. In relation to the former, a paradox is thought individually in the sense that thought as an action 
must have a protagonist. In relation to the latter, we do not have the numbers to be ourselves and also be political actors. We are two actors of the self and two collective actors. Perhaps the most defining condition in our favour is space: not free time as space to write but space when it presents itself as the space of possibility, the invitation to break with the manner in which duty binds itself to space and ascribes in its aesthetic the false notion that philosophy and politics are the same thing. A friendship always needs a new terrain and this is best sought in the place where tacit knowledge is both most evident and hardest to define. This space could be a charred forest without leaves that nevertheless has birds.

Andrew: Richard provided the important impetus for the task, he had the first contact with the theory - I had never read anything on technological disruptions. I was imagining some kind of machine or system that freed the standing reserve from exploitation. So, I got a couple of readings from Richard that were excellent at getting me up to speed and in revealing a theory more inclined to exploit than to reveal exploitation. Mainly I was disappointed in the description and scope of the theory and I think or hope that this comes out in the drafted contribution. In the writing process that followed Richard was taking the theory to new depths while I was trying to point out that we were in the wrong submarine. That was a productive arrangement as it turns out because in very quick time we had a developed a position and I think also that we shared the position. Maybe this is more possible because we have written together before, and that happened in part because as students in the philosophy of education class of 2001 (or thereabouts, but 2001 sounds good to me) we decided to form a word group (not a reading group).

Back to the task of writing about technological disruptions... I'm a bit suspicious, unconvinced, by/with any task to turn a theory into something it was not intended to be. Affordance theory springs to mind (blah blah blah). What I think we are doing is something new, and that comes out in the last paragraph which Richard had initially drafted into the first few sections of the paper, however I suggested moving it to the end, and I think it is a powerful end that starts something new.

Elizabeth G: What I did. It is a Tuesday in August and our group is near completion of our contribution to the collective writing of the article, 'Towards a philosophy of academic publishing' (Peters, Jandrić, Irwin, Locke, Devine, Heraud, Gibbons, Besley, White, Forster, Jackson, Grierson, Mika, Stewart, Tesar, Brighouse, Arndt, Lăzăroiu, Mihăilă, Bernade, Legg, Ozolins, and Roberts, 2016). When I say completion, this may not be true, it may never be in completion; however, the academic labour to date, as applied to a 'natural' resource, that of our minds, seems complete.

This is what I did. The piece I have been co-writing with Georgina Stewart and Carl Mika is section 7, 'Ownership and Rights.' This, I thought, would be a walk in the park - just cover a bit on Intellectual Property and apply it to academic labour. Georgina had written her part first and had raised the issue of indigenous 
knowledge. Yes, I thought, I need to extend my walk in this park, in a meaningful way, down the paths of traditional knowledge in terms of IP interests. This meant more research, another day of academic labour.

Did I find it enjoyable and worthwhile?

Enjoyable: yes, worthwhile: yes. I enjoyed the enquiry, the task of putting together what at first sight seemed simple, but at further investigation was not. I enjoyed writing on from Georgina's text. I did not consider it my right to write 'into' her text as that would seem to transgress the very moral rights that I was writing about. Therefore I regarded her text as complete in itself and I had no right to alter it or add to it. We had not considered these ground rules so had not discussed them. I just followed the IP protocols of collaborative writing that I was addressing and was confident that Carl would finalise the piece with the same approach.

What of my individual academic labour?

In terms of Lockean theory of labour, I was mining the 'natural' resources of my mind, with plenty of thought and energy left over in common for future labouring pursuits. It seemed clear to me that the consequential property, intangible in IP terms, was apparent via the relationship between the labour and ownership rights. The fruits of my labour earned the right to ownership of these ideas in published form, but it also gives rise to my obligation to others in the collaborative contract. This was also clear. It was not a one-woman band.

Cadavre Exquis: Exquisite Corpse

How would our contribution to the article come together with a little bit from Georgina, a little bit from me, and a little bit from Carl? And how will the whole article shape up with all the other different voices? In 1925 André Breton devised a game, Exquisite Corpse, based on the parlour game of Consequences, where each person in a collaborative group adds a bit to the unseen drawing or words to make the whole. Breton's surrealist group would each secretly add a word, a noun, verb, adjective or adverb - or image, a head, body, arm etc. - and fold the paper before passing it on. A sentence or completed drawing would be the result. One of the first games produced this sentence: Le cadavre exquis boira le vin nouveau (The exquisite corpse will drink the young wine) (Pouzet-Duzer 2011), and so the game was named, Exquisite Corpse. Undecidability, paradox and a strange hybridity became the usual outcome in an-other form of reality, a "disruption of everyday logic" as Breton said. Such was the surrealist's attention to chance and automatism

ECC Exquisite Collaborations

To what extent do we, as scholarly writers, adhere to chance or automatism? Probably not much if at all, as we are conditioned already to be critical, to give thought to, and to deliberately mine the resources of our mind in our Lockean version of academic labour. But a possible and paradoxical philosophy of academic publishing may be the outcome.

Perhaps the end result of our collaborative enterprise will be a delightfully uncanny creature, an original form of expression 'fixed' by its published form, 
whose design will be worthy of IP protection. Perhaps we could apply collectively for trade mark protection: ECC Exquisite Collaborations has a nice ring to it, and the commercialisation benefits could be a worthy outcome of our collective labour.

Incidentally Breton and his friend, Paul Eluard talked about the collaboration invoking "love and friendship" (Askew 2005). I thought that was relevant for our Editors' Collective Council, and a relevant place to leave this reflection.

Daniella and Jayne: We both love writing and do it with relative ease. We are both also well accustomed to collaborative writing and have done so over many years. This writing project was, however, something new and different - calling for revised approaches, which we will explain. Our writing experience for the Editors Group was forged out of several very pragmatic factors and led us to an approach that summoned Google Docs as a writing platform that was, as it turned out, unexpectedly helpful for our mutual endeavours:

1. We had never worked together before and were unfamiliar with each other's writing styles or philosophical interests. At the outset all we had in common was a shared curiosity for Open Access in our work, shared interest in Philosophy of Education, joint membership on the newly established Editors Group, and an important conversation about one year-old Ruby in the lobby after the Editor's meeting (more on that soon)...

2. We worked across two separate countries, two institutions, two disciplines. This is not an unusual state of affairs, in general, for philosophers in education; since we are all too often sprinkled around the globe's universities, standing alone, across the occasional education department. But in our case, it meant that there was no possibility of sitting together in the same room to talk through our interests, ideas or issues at hand. No coffee encounters were possible which posed a problem since such rituals have often been critical in previous writing relationships. We had to rely on the goodwill that we had recently established.

3. This task was offered to us at the beginning of a very busy teaching semester and in the midst of several institutional upheavals and other new projects. Not only this, but during the time of writing this paper, Ruby teethed her four first molars (and if you have had teething children in the house, you will remember that the pain and swelling wakes them overnight and they fuss), and Bram, who started 'big school' earlier this year, began to refuse school (and if you have had schoolrefusing children, you might be able to imagine what each morning before school looks, feels and sounds like.) These factors meant that there was an outright incapacity to make writing a top priority accompanied by a degree of anxiety concerning our ability to give the project the time it deserved. In the end we each gave it two sessions - in order. We just wrote and the only way this could be achieved, that we could see, was via google docs because it is an important portal for community, and the creation of intellectual and personal space.

4. I cannot speak for Daniella but I am aware that it was the Ruby connection that meant I had an instinctive rapport at the outset of this project. It was one that 
enabled us to proceed without placing any pressure on one another to meet certain deadlines.

5. As it turns out, Jayne, you are right. Knowing that you understood the demands of early childhood mothering was a key factor in choosing to work with you. It could have been on any of these topic chapters, although I did have a special interest in Open Access, and the idea of openness in general. Not knowing you personally until we met so recently, I had an awareness that I could trust you to appreciate why I could not work to the fast-tracked deadline, and that it was not simply because I wanted a perfect product, nor had the luxury of suffering writer's block.

6. As mothers we both knew the challenges that are faced when any additional demands are placed - willingly or otherwise - on an already crazy academic workload. We also knew that Ruby and her brother, Bram, would be the top priority here and not the article - which by no means denigrates the importance of the article (indeed it became more important as we wrote than either of us had imagined) but it does give it a certain reality and perhaps status in our lives as women who are also nurturers and committed social members of a community.

What these factors made possible was a new way of writing without exchanging a (spoken) word. It seemed to come easily for us - perhaps partially because our quest was very much one of fact finding since neither of us brought much knowledge of the topic to the table, but also we were both accustomed to multitasking and the realisation that comes with it that there is always room for improvement. In this sense it may have been made easier because we were not oriented towards proving ourselves but rather a genuine curiosity in the task at hand, and the commitment to understand OA for ourselves and the group. The net is buzzing with ideas about OA, sometimes in polemic contrasts, accusations of bias, hypocrisy or deceit on both sides and digging into these conflicts raised an understanding in us of just the tip of some deep seated political-economic attitudes, often expressed by authors in terms of their aspirations or suspicions. We hoped simply to tease open this knot, and expose some of the simmering debates. We did not assume to capture the whole picture, and this made our writing exploratory; testing out terms, categories, narratives. It was also made easier because we did not commit to a finished (i.e. published) submission but rather saw it as a beginning effort, and, as such, a contribution to the larger group.

We have learned over time, as writers, that what is written need not be perfect, cannot be perfect. It is what it is at that time - say, $2.25 \mathrm{pm}$ on a Thursday - in between school pickup and during a child's nap or late at night when the children are asleep and the house is quiet. It can be revised, and shared, and opened for reinterpretation perhaps the next day, or perhaps a week later when the next writing space appears. We understood it was by no means complete and this 'unfinished' nature of the project made it less threatening, more achievable and, in consideration of the topic we chose, more appealing. 
Whilst I set up the document on Google and planned out a few notes, it was Jayne who wrote first, in that lengthy way that maps out the terrain and sets the tone and purpose. In doing so, she made it possible for me to 'fill the gaps'; to test out her claims and to gather perspectives on OA that had not yet been given space. This part of our writing process was perhaps more significant than I realised at the time. On reflection, and in the context of our shared understanding of what it is like being a mother-academic, I realise that it was an act of solidarity. In a very real sense, Jayne's act in putting the first elaborated words down made a bridge for me to begin engaging with this unknown, extra challenge that I had not anticipated fitting into my schedule until, literally, the previous week.

At first, I began tentatively, with some very simple conceptual clarification tasks, and then more intensively when I began to grapple with the material objections and variety of shifting forms that the potential of OA can take. Jayne's solidarity with my day-to-day motherhood meant that even if I took longer, she would stand with me. Being a mother-academic working from home, means that often I can snatch only 30 minutes of good, uninterrupted writing time. Like now, when my partner is reading a bedtime story to Bram, and Ruby is already asleep. And then we might spend some time cleaning up and putting the toys away after the day's play. After a week of snatching precious half-hour blocks of writing, I could give over my part to Jayne and she would reply. An extra paragraph or two. A bit of reorganisation, some comments, a question or thought bubble, and then swap turns again.

On each occasion when we went into Google doc (sequenced by an email that simply said "your turn") there was delight in reading what had been discovered in the interim, and a fresh eye on the ideas that had been there before. In some ways it felt as if we were living what we were writing - open, free and accessible across time and space. While we are not so naive as not to understand that there are risks in such approaches, we also trust that the group will respond in kind. We trust this because of our previous liaisons but also, as women, recognise that our writing is never our 'own' in its broadest sense and that all writing is a relational encounter to one degree or other. We give birth to an idea, we nurture it and sustain it as we would our own dear child. But we also know that ideas, like children, grow up, take root in other places. Such is our approach to this writing experience.

Georgina: Responding with a poem is a strategic attempt to bring a different voice to academic writing, and part of my ongoing exploration of the role of narrative modes of writing in educational research. When the muse strikes, the poem quickly appears: words pared to a minimum; each carefully considered, with punctuation to sculpt the rhythm and flow of the overall piece. The last line alludes to the traditional Maori proverb, 'Nau te rourou, naku te rourou, ka ora te iwi' (With your food basket, and my food basket, the people will thrive). 


\section{Collaborative writing}

When we are together we bounce off each other, the ideas grow and spiral, we make plans

It all seems so easy, achievable, what we should be doing.

Then we take our leave, each returning to our own place

Fall once more into the rhythms of everyday - classes, meetings, traffic, home -

Later, sitting down at the computer alone, the excitement is hard to rekindle:

What was it that inspired me so much? They want it when? Are they joking?

After a few such abortive attempts, the desire to get it done builds,

Creates its own imperative: just write something!

I start, as usual, by scribbling on a piece of scrap paper

On this occasion, only four words -

But each of those words becomes a paragraph

Are four paragraphs enough? I hope so, and send them to my collaborators.

Soon the piece is finished. Is it perfect? No, but then what is?

With my little piece, and your little piece, we have something worth saying.

Marek, Sonja, Liz, Susanne: Collaborative writing as a collective emotional Selfie

Collective writing is not something that is conceived easily. There is a striking difference between writing as a 'collective' and co-writing. If we are to point out our experience, it is in a certain way a new form of subjectivity, which has become utilized in a sense as an authorless experience. It does not matter how much or how in-depth each member of the collective was involved in the writing; what their experience or academic rank is: every contributor's presence determined the shape and moulded the argument so the writing became both enriched and authorless as a final product and a gift.

Reflection on one's own writing can sometimes be seen as indulgent. It is also a kind of collective emotional selfie that outlines not only our knowledge and experiences, but also the process of thought in becoming and growing-up in public. We may never reckon whether or not it is a success, and each author might remain unsure about the impact of his or her writing on others. What does this process do in a collective authorship, to all contributors? Does it lessen the burden, ease the process; or does it bring additional complexities and narratives that the authors never considered to be of importance? In a peculiar way, there is both despair and hope in collective writing. Authors, on the one hand, are unaware and lack any knowledge about how the writing will end, and on the other, they are very much aware that it will, and must, in fact end well. 
Collective writing also creates an extra pressure of the performance - the experience that there are other subjects waiting for our words, for our contribution, can be at the same time very daunting and liberating. There is an element of international solidarity that becomes an essential $\operatorname{cog}$ in the process: different backgrounds, countries, time zones. The reflection on the collective authorship serves as a mirror on our current thinking and academic work. It reflects also where we are currently in our lives, our personal and professional endeavours and relationships are interlinked and cannot necessarily be ignored; but quite the opposite, it becomes the productive space that allows us to produce more thorough examinations of ourselves as subjects-in-writing-process. We are the subjects-inwriting-process that through a collective authorless authorship allow for a place of resistance to the machinery of demands for clearly outlining the contributions outputs - of each author.

As a productive space, a gift to and from all of us, the writing process then becomes some form of a mask, allowing us, simultaneously hidden and exposed, to take certain risks. Masked in a sense behind our collective pseudonym, we are freed by the knowledge that we are building a greater united whole, with each of our contributions, greater than a singular effort, sparked and spurred on not only by each other's thoughtful input, how much we revere the other authors in our group, their standing in the academe, or their important work in the greater educational and academic publishing milieu, but by the collective energy and buzz emanating from the shared expectations, and collective intercontinental and intercity dynamics. Collectively we have shaped something then that is determined by more than a solitary stance. Our humble individuality has become multiplied, in this temporary exilic departure from ourselves, but through ourselves, opening possibilities for distancing ourselves towards a more irreverent, ruthless whole.

But maybe, as the collective strength of all of our contributions determines the shape and cohesion of the eventually-to-be-published whole, the pseudonymic mask also offers a space to hide our fear. The same reverence towards our colleagues' thought contributions can lead to a wary tentativeness. Standing on the precipice of uncertainty - will my contribution measure up? What can my thinking add? Nevertheless, taking strength from the idea that thought itself is always a form of dissidence, we take the leap. We compile our individual thoughts together in a collective expectation to add to the whole, relinquishing expectations of knowing, or certainty, subjects-in-writing-process, to think through and contribute not only to the final 'thing,' nor only to the process, but to ourselves and to each other.

\section{Experiences and Challenges - Moderators}

Richard: Moderation, in the context of the previous article (Peters et al., 2016), is not to argue for an adjustment in relation to the value of one text to another. The symmetry already exists on account of the number of words that each author has to work with and the presumption that the maximum diversity of approach in the 
collective will render not a universal picture but one where its problems are approachable and able to be engaged with. In this sense, we are both breaking with professional expertise and creating a beginning without end; a colloquial revelation of serious and practical consequence! Moderation of engagement and collection is here an act of caring for the aperture and the need to be hospitable without conditions.

Of course, our diversity creates conflict but this seems mostly to do with the challenge of transforming the academic habitus and the fact that we have constituted ourselves as academic performers. In the previous article, there is a different kind of performance: a leap without time for research and a return to the idea of the academic as an already intellectual, as already innovative and an already creative being. Observation of the process of collaboration and collective contribution - choice of collaborator, the choice of a section topic (the articulation of which was already ascribed) and 500 words each, written in collaboration, and an initial time-limit of one week - has me thinking of Drucker's words: "Innovation, as we now use the term, is based on the systematic, organized leap into the unknown. Its aim is to give us new power for action through a new capacity to see, a new vision. Its tools are scientific; but its process is of the imagination, its method the organization of ignorance rather than that of known facts" (1959, p. 13).

When there is both a limit on time available and a word limit, academic performance can be threatened. A leap into the unknown can only be structured and systemized up to a certain point: the unknown by definition presumes that the actor and his or her collective will always be unprepared for what they are about to meet. Yes, our expertise tells us that we have the scientific tools that enable us to organize known facts, but this is not all we need for such a project. In this instance, the task was to stand, speak and disappear back into the profession; the action of speaking being the action of thought. The organization of our ignorance of an already chosen topic, that we individually accepted to write on, is what makes actors and listeners.

The technology of this genre of collective writing cannot be self-serving and, as such, its process becomes collaborative not just with one's collaborator or with the collective as a whole, but more importantly with those who populate the realm of the problems that are herein spoken to. Technology is only the means, not the end: as a means it is more important that we transform ourselves than it is that we transform technology as an artefact: the former we cannot do for its own sake (we must do it for others), while the latter we can. When there is conflict it needs to be treated as soft conflict: I have to put my hand over my mouth as each actor of the self is exposing him or herself in a new way - as I am too. This requires the utmost respect and humility, something I must learn. When working with a collective producing new works in such a genre, the moderator commits many errors as he tries to find his place in the spectrum of experience that falls between his listening and his actions. When listening to Jacotot's (Rancière, 1991) conversation with the 
parents of his students and to David Bowie's (1999) description of his conversation with his audience, what is happening is already happening out there. This is their report and the report of this editorial collective.

Petar: Online moderation is my bread and butter - working in digital distance education since the beginning of my career, my daily work has always consisted of moderating numerous distance students. Then there is my research - working from the periphery of Europe, I often co-write with colleagues from all around the world. As (co-)editor of edited books and journal articles, I also need to manage a vast number of physically remote writers. Finally, various digital learning development projects I have been a part of, in and beyond the European Union, have a strong component of managing distance teams. In the age of online collaboration, I guess that my case is far from unique... Therefore, it is worthwhile to ask: What, if anything at all, makes the act of moderating collaborative writing unique?

Power relationships seem a good place to start this inquiry. In teaching, I am obviously positioned above students; in editing, my judgement decides whether something will be published; in projects, I am either the leader or the subordinate. It is only in co-writing, that I am completely equal to my partner(s). Yet, it is quite rare to co-write with unknown people - typically, our writing partners are carefully selected amongst our colleagues and friends. In this project, however, the majority of my partners are almost complete strangers - yet everyone has an equal say at how this paper will look like. Such radical equality amongst strangers requires a leap of faith, and establishing trust between strangers. In this project, all contributors have all been gathered by Michael, whom I deeply respect. So my trust, and my leap of faith, has a name and a face: instead of trusting you, unknown stranger, I trust that Michael did a good job in inviting you. I wonder, what would happen if all collaborators were my close friends? Vice versa, what would happen if we were just randomly selected from an academic database?

As moderator, I am in permanent contact with everyone included in the project. I get to see draft versions of every contribution; I receive all complaints. In this sense, my position is different from all others. For instance, the majority of contributors to this piece could not read other people's contributions before writing their own - in this sense, their contributions are clean of peer influence. However, I first received all contributions, then I read them, then I formatted them, then I reread them, and I fiddled with their sequence. Unlike other contributions, therefore, my piece is heavily influenced by all other pieces. My initial impulse was to simply skip writing own impressions - conceived in a radically different context, they are simply incommensurable with the others. When, however, Richard proposed that we should include a separate section on moderators' impressions, I realized that these might be of value - for as long as we do not put them in the same pot with the rest. I wonder, what would be moderator's position in a differently themed paper?

Then, there is the pure 'mechanics' of moderation. In student-teacher relationships, project partner relationships, author-editor relationships, and even 
writer-writer relationships with people I know well - I can be strict about deadlines, I can openly express (dis-)agreement, I can nag people to do the work. In this project, however, things are radically different. No-one get a mark for this at the end of the semester; no-one is getting paid for this collaboration; the article with more than ten authors will not significantly (if at all!) contribute to anyone's tenure... So who am I to interfere with authors' daily lives and push them to do something? Out of 23 authors in the original article, only 16 people agreed to this follow-up. I would definitely like to get better take-up, but how should I go about it? And how can I motivate people who are already there?

Every time I send a group e-mail to 23 addresses, I am well aware that I am using quite a lot of collective work time -23 people, times 5 minutes of reading, equals 2 hours! And if everyone spends just a couple of hours in drafting their contributions, reading other people's contributions, and then reading the whole article and commenting on it - workload goes beyond the roof. Obviously, contributing to an article such as this is based on love for inquiry, intellectual curiosity, passion for new, and tolerance for my (and other people's) errors. So how do you moderate love, curiosity, passion, and tolerance?

One of the most important aspects of all writing is timing - this is not a Wiki, and we are here to produce a complete article. Therefore, the project cannot go forever - it needs a reasonable timeframe, and an end. Projects that are too short, will leave people frustrated; projects that are too long, will make everyone lose their interest. Long ago, Hegel wrote: 'The owl of Minerva spreads its wings only with the falling of the dusk.' (Hegel, 1991, p. 23) So what is the right timing for this paper? When should I say, 'No worries, take your time,' and when should I say 'This is the deadline, and late submissions will be ignored?' Timing, like musical rhythm, is always a matter of feeling... But how do you develop a feeling for people you do not know?

This moderator's rant could go on and on... Saying too little puts the whole project in jeopardy - how can I expect other people to diligently work on this, if I am not giving my fair share? But saying too much is probably even worse - this project equally belongs to all its contributors, I am only the individual means to the collective end. So if I continue this small text, and monopolize the paper, then I deferred the whole purpose of collective writing. Moderation - surprise, surprise should be moderate... So what can I do about that? I will wrap up the argument, and say that the act of moderating collaborative writing definitely seems like a unique experience. Then I will just leave these unfinished impressions-and hope that someone will pick them up further.

\section{Emerging Themes and Challenges}

Georgina: The open invitation to reflect on the process of collective writing for this article resulted in an impressive breadth and quality of responses being received. As already noted, the nature of the pieces themselves suggested the 
section headings of the paper, and the sequence in which the contributions appear above. The authorial question - who is speaking? - is prompted by the 'borders' between contributions, which are left visible in this patchwork paper. Ultimately, the article speaks in the collective voice of the Editors' Collective.

Emerging from the contributions are the following themes:

1. Various genres are represented: the responses range in type from synoptic analyses supported by literature, to personal narratives and accounts of experience, to poetry, to reflections on academic work as performance.

2. Seen positively, this collective way of working stakes a claim as cutting-edge research; but the flipside is a nagging worry about 'navel-gazing,' 'vanity presses,' and the like.

3. The contributions pay attention in different ways to the material circumstances of academic labour, located in time and space; straddling intellectual, emotional and physical aspects of the identity of authors; and exploring the multiple demands on our time, both within and beyond the institutional contexts of our employment.

4. Many responses spoke of the fluidity and opportunism that characterizes the lives of today's academics - for example, squeezing in 30 minutes each evening to review the collaborative Google doc.

5. There is an interplay between the demands of collective writing and the network of friendships that binds together the members of the Editors' Collective, which suggests a need to maximise time spent together in person at conferences and meetings. Not everyone is friends with everyone else in the collective, but the friendships 'hold hands' so that 'your friends are my friends' within the group.

The challenges are obvious within the above-listed themes:

1. The challenge of time: everyone reports being expected to do more and more.

2. The challenge of visibility: working on projects for the Editors' Collective may not be recognised by employers.

3. The challenge of distance: personal, geographical, disciplinary, linguistic and other forms of distance may prevent us from collaborating as productively as we might.

In collective writing, the contributors identified some of the following benefits:

1. The benefit of productivity: collective writing is often understood as more productive, and sharing workload is listed as one of the key benefits.

2. The benefit of creativity: collective writing is typically seen as creative and innovative - it is seen as less predictable, and it is said to develop (grow and spiral) new ideas, improve research methods, open more possibilities.

3. The benefit of emotions: authors report various emotional benefits, such as developing mutual connections through motherhood. Collective writing is seen as liberating, and provides a space to hide own fear of exposure. 
4. The benefit of politics: collective writing is said to upset the neoliberal ethos of the contemporary university; it is also considered as a natural counterbalance to rabid and prevalent individualism.

5. The benefit of originality: authors compare this article to various genres of collective writing from the Bible to editing books and journals, and indicate that experiments like this article might be seeds of a new genre of academic writing.

\section{Discussion}

Leon: The writers here are thinkers too; what has been conceived in this writing project (following hard on the heels of the earlier "Toward a Philosophy of Academic Publishing") is a metatheoretical exercise of sorts. It is a dwelling on the possible outcome of having brought together a disparate, yet unified, group of colleagues, associates and friends, to engage in the process of reflecting and writing the earlier article as a collective. It is a writing about writing, and a thinking about the business of thinking about writing. Critics might suggest this is mere navel-gazing; we suggest it is an entirely appropriate philosophical, theoretical and pedagogical activity - one, we might add, that is keenly required in an overly-reductionist education world.

One dimension of education life in the academy that is particularly redolent of this reductionism is the regime of performative writing - writing for publication, not for the benefit of the public, or to make valuable research results known, but for the potential value of the well-chosen journal, or the successful international publishing house. The translation of publication by individual academics into the potage of research funding to universities drives significant levels of activity in universities. This all-consuming activity calls into question, however, the motives of busy academics to share in a writing project that scarcely identifies their individual contribution to the project.

This collective of writers, editors, academics and educators works in the context of significant enhancements to print and authorship, brought upon by digitisation and interconnectivity. The postmodern challenge to authorial intent is provided an added facet by the social media notion, 'everyone is an author.' Unlike social media, however, we, the writers, continue to work under the aegis of collective responsibility and peer review - with the twist that this responsibility and review is openly transparent. Or is it? Despite this openness, it is not necessarily clear who has shouldered precisely which responsibility, nor is it clear the extent of individual responsibility, when a collective of writers gathers to produce an article such as this one. In the world of metrics and measured accountability, who takes the primary credit for the published output? Our collective of writers simultaneously troubles, and is troubled by, questions of credit and responsibility.

Perturbations notwithstanding, collective writing presents opportunities as it presents challenges. Some of the challenges have been mentioned; there are others, however. Clearly time and distance present challenges, though electronic 
technology and digital communication, for all its hooks, presents a ready solution to the spatial and temporal challenges of working in busy cities or centres that are geographically apart. The opportunity of spending quality time in the company of kindred spirits is not to be underestimated, however; the conviviality of company, refreshment and related interests is a stolen pleasure from the frenetic pace of daily work. Perhaps we (writers and readers) may learn much from the example of Paulo Freire, who engaged in 'talking books,' such as his collaboration with Ira Shor that produced A Pedagogy for Liberation. Here, Freire suggested that a talking book "can be serious without being pedantic...rigorously approach[ing] the ideas, the facts, the problems...in a light style, almost with a dancelike quality, an unarmed style" (1987, p. 2), to which Shor replied, "I hope we find a dancing style. So, let's take turns being poetic and comic and profound" (p. 3).

While the act of shared writing suggests a shared commitment, does it imply or presuppose shared views, opinions and beliefs? Writing on the same subject, two authors may find they are working from different perspectives that may test the limits of their friendship and collegiality. The greater challenge is finding a way to reconcile disparate perspectives to create a harmonious end result. Perhaps, however, harmony is less desirable than discordance, which may itself create new possibilities for novel thought. The discordance created by bringing together two (or more) writers with a common goal but with uncommon background interests, experience or ontological assumptions, does indeed open new possibilities, and can lead to a Gadamerian 'fusion of horizons,' which does not imply agreement, but rather a shared understanding (Vessey, 2009), and the possibilities for on-going development. Metaphors of midwifery, nurture and collective care spring easily to mind, with commitment to the birth and growth of new ideas being more important than individual egos. Underpinning this commitment, is a deep vein of trust - in the ability of all contributors, in their willingness to contribute, and their mutual faith in one another, even if some scarcely know the other.

\section{Conclusion}

Richard: 'Collective Writing: An Inquiry into Praxis' comprises a series of individual and collaborative reflections upon the experience of contributing to the previous and first text written by the Editorial Collective: 'Towards a philosophy of academic publishing' (Peters, Jandrić, Irwin, Locke, Devine, Heraud, Gibbons, Besley, White, Forster, Jackson, Grierson, Mika, Stewart, Tesar, Brighouse, Arndt, Lăzăroiu, Mihăilă, Bernade, Legg, Ozolins, and Roberts, 2016). These texts have been collectively written, albeit in a slightly different manner, so the reflections are inevitably drawn from both writing experiences. There is collaboration in both, between individuals and the idea of the collective and between authors who have collaborated on the same section. The second text was born out of the first - not as a means of extending the discursive act, but in response to an internal need to stand back and re-engage with something most of us have never done before. 
The conditions that make the second feature of this double-act are necessary and multiple. I am not going to write about these conditions as all academics, who have gone on to act in an editorial capacity, will know that the paradox that these conditions comprise. That is, the conditions under which critical reflection is invited, encouraged, permitted, tolerated or prohibited are particular to the distinctive situation of the academic and furthermore can only be thought philosophically according to his or her intellectual capacity. If there is something to say here, it is that the ambiguous domain in which collaborative writing engages educational and publishing institutions should not be reined in and shaped too quickly. After all, if collective writing is to reflect a genuinely new development, it needs to be engaged not only collaboratively - involving academics and institutions (and most definitely students too) - but also collectively. This, to say the least, is a complex endeavour.

What does it mean that collaborative reflection should be shaped collectively? We are in a very early phase of the age of creative col(labor)ation (Peters and Jandrić, 2016: 194) in knowledge production, education, (academic) publishing, and in the transformation of political economy in general. Therefore, it is probable that collaborative and collectively shaped reflection can only be understood through an action for which we are unprepared. The collaborative and collective action is a thing of learning-by-doing. In the first instance, it is an act that cannot be instrumentally selective with regards to who the participants should be. Furthermore, it is an act that cannot be selective about what is said - the nature of what is written is largely circumstantial.

This approach is disruptive when it comes to the need to provide performative objectives that articulate outputs. Financial planning in the existing model immediately falls over. Clearly there are new sensations. In neo-liberalism giving permanence to its methodology for future vision, the unexpected departures and the creation of new orientations appear in the social space where adventure is demanded. To put it graphically, these new sensations may belong to another category of public good (see Lévy, 1997). Instead of writing being thought of as a measurable output that uniquely serves the commercial imperatives of the commodity space in which we all perform, reading writing, speaking and listening, to quote Nesta and Elizabeth J.'s introductory notes, must once again begin to be thought of as collaborative acts - and as knowledge acts rather than knowledge assets, as economists are prone to think of knowledge.

Creative col(labor)ation in knowledge production (Peters and Jandrić, 2016: 194) is in a formative stage of its development and the directions for its further growth, as well as the tools for its evaluation, will come from the actors responsible for the development of this field. In making our collective path by walking together (McLaren, 2005: 160), we necessarily engage in the act of critical praxis, where theory and practice shape various aspects of our interactions and their products. At the moment, collective writing seems to offer a dynamics of knowledge production which is positioned slightly external to economic relationships. However, this is far 
from enough: an analysis needs to be done of the co-opting of academic activities by economics and the transformation of these activities into a form of work that is exclusively economic. Without this, we will not be able to understand how to avoid that which is written being reduced to an information and commercial asset, when it should become a reflection of the presence of new forms of participation, collaboration and transformation. When 'the knowledge space' (Lévy, 1997: 138141 ) is no longer a disciplined subset and logistical asset of "the commodity space" (ibid.: 135-138), creative col(labor)ation (Peters and Jandrić, 2016: 194), and its embodiment in collaborative and collective writing, begin to address the problem of forming new collective intelligences.

\section{NOTE}

1. See the Editors' Collective website: www.editorscollective.org.nz/. Biographical information for all authors is available from the website. Authors are listed in order of authorship of sections. All citations of this paper should include the full list of authors.

\section{REFERENCES}

Askew, L. (2005). André Breton, Nusch Eluard, Valentine Hugo, Paul Eluard. Exquisite Corpse c. 1930. Tate. http://www.tate.org.uk/art/artworks/breton-eluard-hugo-exquisitecorpse-t12005/text-summary

Barnett, R. (2015). Conceiving the university. Psychosociological Issues in Human Resource Management, 3, 85-94.

Bowie, David (1999). David Bowie speaks to Jeremy Paxman on BBC Newsnight. https://www.youtube.com/watch?v=FiK7s_0tGsg

Drucker, P. (1959). The landmarks of tomorrow. Melbourne: Heinemann.

Ede, L. S., \& Lunsford, A. A. (1990), Singular texts/Plural authors: Perspectives on collaborative writing. Carbondale, IL: Southern Illinois University Press.

Field Belenky, M., Clinchy, B. M., Goldberger, N. R., \& Tarule, J. M. (1997). Women's ways of knowing: The development of self, voice, and mind. New York, NY: Basic Books.

Haddad, N., \& Wang, K. (2015). Participatory global citizenship: Civic education beyond territoriality. Journal of Self-Governance and Management Economics, 3, $26-44$.

Hegel, G. F. W. (1991). Elements of the philosophy of right. Cambridge: Cambridge University Press.

Lăzăroiu, G. (2015). The role of the management consultancy industry in the knowledge economy. Psychosociological Issues in Human Resource Management, 3, 71-76.

Lee Hotz, R. (2015). How many scientists does it take to write a paper? Apparently, thousands. The Wall Street Journal, August 10.

Lévy, P. (1997). Collective Intelligence: Mankind's emerging world of cyberspace. Trans. R. Bononno. London: Plenum Trade.

McLaren, P. (2005). Capitalists \& conquerors: A critical pedagogy against empire. Lanham, MD: Rowman \& Littlefield.

Peters, M. A., \& Jandrić, P. (2015). Learning, creative col(labor)ation, and knowledge cultures. Review of Contemporary Philosophy, 14, 182-198. 
Peters, M. A., Jandrić, P., Irwin, R., Locke, K., Devine, N., Heraud, R., Gibbons, A., Besley, T., White, J., Forster, D., Jackson, L., Grierson, E., Mika, C., Stewart, G., Tesar, M., Brighouse, S., Arndt, S., Lăzăroiu, G., Mihăilă, R., Bernade, L., Legg, C., Ozolins, J., \& Roberts, P. (2016). Towards a philosophy of academic publishing. Educational Philosophy and Theory, 48, 1401-1425.

Pouzet-Duzer, V. (2011). The exquisite corpse. Chance and collaboration in Surrealism's Parlor Game, by Kanta Kochhar-Lindgren, Davis Schneidermann, and Tom Denlinger, University of Nebraska Press, Lincoln \& London, 2009. Papers of Surrealism, 9, Summer. http://www.surrealismcentre.ac.uk/papersofsurrealism/journal9/acrobat_files/ Exquisite\%20Corpse\%207.9.11.pdf

Rancière, J. (1991). The ignorant schoolmaster: Five lessons in intellectual emancipation. Kristin Ross, trans. Stanford, CA: Stanford University Press.

Sevilla-Pavón, A. (2015). Examining collective authorship in collaborative writing tasks through digital storytelling. European Journal of Open, Distance and E-Learning, http://www.eurodl.org/?p=current\&sp=brief\&article $=685$

Shor, I., \& Freire, P. (1987). A pedagogy for liberation: Dialogues on transforming education. Westport, CT: Bergin \& Garvey.

Vessey, D. (2009). Gadamer and the fusion of horizons. International Journal of Philosophical Studies, 17, 531-542. doi: 10.1080/09672550903164459. 